\title{
The Effect of Saline Infusion on Sodium Reabsorption by the Proximal Tubule of the Dog*
}

\author{
John H. Dirks, $\dagger$ William J. Cirksena, $\$$ and Robert W. Berliner with the \\ TECHNICAL ASSISTANCE OF NORDICA GREEN
}

\begin{abstract}
(From the Laboratory of Kidney and Electrolyte Metabolism, National Heart Institute,
\end{abstract} Bethesda, $M d$.)

A depression of sodium reabsorption has recently been shown to occur in the dog nephron after intravenous saline administration. De Wardener, Mills, Clapham, and Hayter $(1,2)$ and Levinsky and Lalone (3) have demonstrated that the increased sodium excretion can occur despite reduced glomerular filtration rate and in the presence of high levels of circulating adrenal cortical hormones and vasopressin. The natriuresis was also independent of the renal nerves and of changes in the sodium concentration of plasma, plasma proteins, and hematocrit. Such results have suggested that an additional unidentified humoral agent is involved in sodium reabsorption by the tubules. The precise locus of this effect on the tubules has not yet been defined, but several investigators have favored a distal site (4-6). Rector, Van Giesen, Kiil, and Seldin (7), on the other hand, interpreted the increased generation of free water and increased potassium excretion during hypotonic saline infusions as indicating a more proximal site of the diminished sodium reabsorption.

The proximal tubule has been considered to reabsorb a constant fraction of the filtrate, a view first offered by Smith (8). Micropuncture studies in the rat proximal tubule by Lassiter, Mylle, and Gottschalk and by Giebisch, Klose, and Windhager $(9,10)$ were largely in accord with this

* Submitted for publication February 12, 1965; accepted March 11, 1965.

Abstract submitted to the Federation of American Societies for Experimental Biology, April 1965.

$\dagger$ Successively, Fellow, Medical Research Council of Canada, and Visiting Associate, National Heart Institute, Bethesda, Md. Address requests for reprints to Dr. John H. Dirks, Laboratory of Kidney and Electrolyte Metabolism, National Heart Institute, Bethesda, Md. 20014.

¥ Special Fellow, Office of the Surgeon General, Department of the Army, Washington, D. C. interpretation since, after infusion of hypertonic sodium chloride solutions, there was no change in the fraction of sodium reabsorbed in the proximal tubule despite large changes in filtered load. An exception to this was encountered in the study of Giebisch and coworkers (10), when the excreted sodium exceeded $12 \%$ of the filtered load. Under these circumstances a depression of the fraction of sodium reabsorbed in the proximal tubule was observed.

In micropuncture studies of the dog proximal tubule we found tubule fluid to plasma (TF/P) inulin ratios significantly lower during saline diuresis than in hydropenic animals. To evaluate this finding more precisely, a method of collection from the same proximal tubule segment before and after salt loading was used. We found that the fraction of filtered sodium reabsorbed in the accessible portion of the dog proximal tubule is independent of changes in the rate of glomerular filtration but that the fractional reabsorption of salt and water is markedly depressed by salt loading.

\section{Methods}

Studies were performed on 26 mongrel dogs weighing 10 to $30 \mathrm{~kg}$. Dogs were anesthetized by rapid iv injection of $25 \mathrm{mg}$ per $\mathrm{kg}$ sodium thiopental (Pentothal sodium ${ }^{1}$ ) administered as a $2.5 \%$ solution in distilled water. Supplemental thiopental was given during the experiment as necessary. An endotracheal tube was inserted in all experiments. Indwelling polyethylene catheters were inserted into a foreleg vein for saline infusion, a jugular vein for inulin infusion, and a femoral vein for periodic blood sampling. The right ureter was exposed by a suprapubic incision and catheterized just proximal to the bladder. The right kidney served as a control in all experiments. The left "experimental" kidney was exposed through a flank incision, and the renal artery and vein were gently dissected free 2 to 3 inches from the hilum of the kidney. Nerves were cut as neces-

1 Abbott Laboratories, North Chicago, Ill. 
sary, but no attempt was made to denervate the kidney completely. The left ureter was catheterized close to the kidney; the kidney was supported and illuminated for micropuncture as previously described (11). A square centimeter of capsule was removed with the aid of a microcautery and the surface bathed with mineral oil. Small amounts of heparin were placed on the surface to retard fibrin formation.

Collections of fluid from convolutions of proximal tubules were made as follows: The micropipette, filled to the tip with colored mineral oil, was inserted into the tubule and a small amount of oil injected into the lumen. The oil drop was permitted to flow on distally, and tubule fluid was allowed to flow spontaneously into the pipette. In this manner, suction, which could conceivably alter glomerular-tubular pressure relationships, was avoided. The volume of fluid collected varied from 0.03 to $0.10 \mu 1$ or more. Each sample was examined microscopically to exclude the presence of erythrocytes. The time required for collection was measured in each instance.

Three to 12 tubules were punctured during the control period in each experiment. After each puncture, the tubule segment was marked by gently layering nigrosine dye onto adjacent segments with a separate pipette. In each case a drawing was made of the sampled segment, and the juxtaposed segments and the marked tubule were related to tubules injected earlier with nigrosine and spaced over the decapsulated surface as landmarks. These steps insured accurate reidentification of the punctured tubule segment later in the experiment. The same segment was then resampled during a repeat control collection period, after saline infusion, or after clamping of the renal artery. An effort was made to randomize the order of recollection in all experiments. Two to five recollections could be made from a given tubule. Only occasionally were tubules injected with latex and later dissected out. Previous studies (11) have shown that all tubule segments on the surface of the dog kidney are proximal tubules. Some recollection experiments could not be completed because of excessive pulsatile motion and fibrin formation.

Four types of micropuncture recollection experiments were carried out: 1) isotonic saline controls and 2) hydropenic controls, in which repeated collections were made from the same tubule segments during continued saline diuresis or extended hydropenia, respectively, to evaluate the validity of the recollection technique under these conditions; 3) isotonic saline and 4) hypertonic saline diuresis, in which collections were made from the same tubule segments before and after the infusion of $0.9 \%$ or $5 \% \mathrm{NaCl}$, respectively. Additional collections were made after partial clamping of the left renal artery in animals infused with isotonic saline. All dogs were deprived of water 12 to 18 hours before an experiment. At this time, two dogs in the isotonic saline diuresis group were given $10 \mathrm{mg}$ of desoxycorticosterone acetate (Percorten acetate ${ }^{2}$ ) and $5 \mathrm{U}$ vasopressin tannate in oil

2 Ciba Pharmaceutical Co., Summit, N. J.
(Pitressin tannate in oil ${ }^{3}$ ) intramuscularly. One-half hour before each experiment, each dog received $5 \mathrm{mg}$ desoxycorticosterone in oil. In addition, each dog received a prime of $1 \mathrm{mg} 9 \alpha$-fluorohydrocortisone ${ }^{4}$ at the start of the experiment and a constant infusion of $2 \mu \mathrm{g}$ per minute throughout the experiment. Similarly, a prime of vasopressin (Pitressin ${ }^{3}$ ), $33 \mathrm{mU}$ per $\mathrm{kg}$, and continued infusion of $100 \mathrm{mU}$ per $\mathrm{kg}$ per hour were administered. One dog in the hypertonic saline diuresis group received the identical amount of mineralocorticoids but no vasopressin. None of the other dogs received supplemental hormones.

In the six isotonic saline control experiments, dogs were infused with $0.4 \mathrm{ml}$ per $\mathrm{kg}$ per minute $0.9 \% \mathrm{NaCl}$ for 30 minutes and then with $0.2 \mathrm{ml}$ per $\mathrm{kg}$ per minute to the conclusion of the experiment. Control collections were made when the diuresis was established. Fluid was recollected from the same tubule segments after an interval of at least 1 hour to simulate conditions in the other experiments.

Collections in seven hydropenic control animals were similarly made in the absence of saline infusion in the control and recollection periods.

In nine isotonic saline infusion experiments, control collections were obtained during hydropenia; then $1.0 \mathrm{ml}$ per $\mathrm{kg}$ per minute of $0.9 \% \mathrm{NaCl}$ was infused for 20 to 25 minutes ( 350 to $450 \mathrm{ml}$ ) followed by a constant infusion of $0.5 \mathrm{ml}$ per $\mathrm{kg}$ per minute to the termination of the experiment. When urine flow had increased to 3 to 4 times the control flow rate, the previously punctured tubules were resampled. Tubules at this time appeared full, and fluid entered the pipette rapidly. In six experiments a screw clamp was then placed around the single left renal artery and tightened. Decreasing renal volume was observed with the stereomicroscope, and the clamp was adjusted until urine flow from the experimental kidney was reduced to one-third to one-half the flow in the control kidney. Tubule segments were then sampled for a third time, and, occasionally, a fourth time during increased clamping. The kidney after clamping was smaller and softer. Tubules often appeared narrower and more pale. However, samples were collected almost as rapidly as in the unclamped recollection period.

In three hypertonic saline infusion experiments $5 \%$ $\mathrm{NaCl}$ was infused in amounts to yield a dose of $\mathrm{NaCl}$ approximately the same as that of the isotonic saline infusion experiments, i.e., $0.2 \mathrm{ml}$ per $\mathrm{kg}$ per minute of $5 \%$ $\mathrm{NaCl}$ for 20 to 25 minutes (100 to $125 \mathrm{ml}$ ) followed by $0.1 \mathrm{ml}$ per $\mathrm{kg}$ per minute to the conclusion of the experiment. Tubule segments were resampled after urine flow had increased to 3 to 4 times the control flow rate. Fluid was also collected rapidly during hypertonic saline diuresis. The renal artery was not clamped in these experiments.

In all experiments, during collection of tubule fluid samples, 15-minute urine collections with mid-point blood sampling were obtained for determination of inulin clear-

${ }^{3}$ Parke, Davis \& Co., Detroit, Mich.

4 The Upjohn Co., Kalamazoo, Mich. 
TABLE I

Isotonic saline control

\begin{tabular}{cccc}
\hline \hline Tubule & $\begin{array}{c}\text { Initial } \\
\text { collection } \\
\text { TF/P* inulin }\end{array}$ & $\begin{array}{c}\text { First } \\
\text { recollection } \\
\text { TF/P inulin }\end{array}$ & $\begin{array}{c}\text { Second } \\
\text { recollection } \\
\text { TF/P inulin }\end{array}$ \\
\hline 1 & 1.55 & 1.75 & \\
2 & 1.56 & 1.67 & \\
4 & 1.62 & 1.66 & 1.81 \\
7 & 1.65 & 1.81 & 1.67 \\
8 & 1.59 & \\
\hline
\end{tabular}

* $\mathrm{TF} / \mathrm{P}=$ tubule fluid to plasma ratio.

ance and sodium excretion. Sodium excretion was not measured in the saline control experiments.

Sodium in plasma and urine was determined with a Baird flame photometer DB-5. Inulin in plasma and urine was determined by the anthrone method of Führ, Kaczmarczyk, and Krüttgen (12). Inulin in tubule fluid was determined by a modification of the microanthrone method of Hilger, Klümper, and Ullrich (13). Reagent was freshly prepared by dissolving $100 \mathrm{mg}$ recrystallized anthrone in $175 \mathrm{ml} 70 \%$ sulfuric acid (14). Small quantities were filtered through a fritted glass filter just before use. The concentration of anthrone used in these studies lessened the problem of recrystallization at the time of reading. The reaction mixture was prepared by transferring $10 \mu \mathrm{l}$ of reagent to a depression in a carefully cleansed siliconized plate; 0.028 $\mu 1$ tubule fluid was transferred to the reagent drop with a pipette constructed of $44-\mu$ i.d. constant bore capillary tubing. Reagent and sample were thoroughly mixed by repeated drawing into a length of $1.0-\mathrm{mm}$ i.d. glass tubing tapered at both ends. The unused end was heat sealed after drawing the mixture into the opposite end. The mixture was then shaken to the sealed end and the opposite end sealed with plasticine to avoid heat charring of any of the mixture adhering at the tip. Samples were kept in an ice bath to prevent color formation before incubation. The sample pipette was rinsed with $70 \%$ sulfuric acid and water, and acetone dried between each sample. Duplicate inulin determinations were made on approximately two-thirds of the tubule fluid samples.

The color reaction was carried out in a constant temperature water bath at $37^{\circ} \mathrm{C}$ for 50 minutes. As also noted by Davidson and Sackner (14), we have found the results more reproducible with incubation at this lower temperature for a longer period of time than at $56^{\circ} \mathrm{C}$ for 10 minutes.

The optical density of the incubated samples was determined against a reagent blank in one of a pair of matched flow-through platinum core cuvettes, using a Beckman DU monochromator as a $636-\mathrm{m} \mu$ light source with an Aminco photomultiplier photometer. One-half of the mixture was rinsed through the cuvette to clear the remainder of the previous sample, and the rest was used for reading. A $636-\mathrm{m} \mu$ interference filter was placed between the sample and the photomultiplier tube to narrow the spectrum of wave lengths passing the cuvette core.
The reagent blank and sample cuvettes in their holder were fixed in two dimensions in an Aloe cuvette carriage adapted to the monochromator. The carriage allowed fine control of cuvette movement across the light source. With each sample, cuvette position was adjusted until peak light transmission was achieved. Optical densities were then compared to those of similarly prepared 1.0, $2.0,3.0$, and $4.0 \mathrm{mg}$ per $\mathrm{ml}$ fructose standards to obtain inulin concentrations.

Twenty-two standard fructose solutions handled as unknowns in this manner gave a standard deviation of $\pm 4.7 \%$.

Tubule fluid to plasma inulin ratios were calculated, with the plasma inulin interpolated to the mid-point of the sample collection when there were changes in plasma inulin concentration.

\section{Results}

Isotonic saline controls. Table I summarizes a typical experiment showing the effect of recollection from the same tubule segment on salt and water reabsorption as indicated by $\mathrm{TF} / \mathrm{P}$ inulin ratios.

Figure 1 shows results of 49 paired collections during saline diuresis in six dogs. The inulin $\mathrm{TF} / \mathrm{P}$ in the second collection is plotted against the initial ratio from the same tubule segment. Deviation from the initial ratio occurs on both sides of the identity line. The mean change in inulin $\mathrm{TF} / \mathrm{P}$ was $+0.01(\mathrm{SE} \pm .016)$. Deviation of points from the identity line indicates the cumulative methodological error in the collection and handling of samples, determination of plasma and

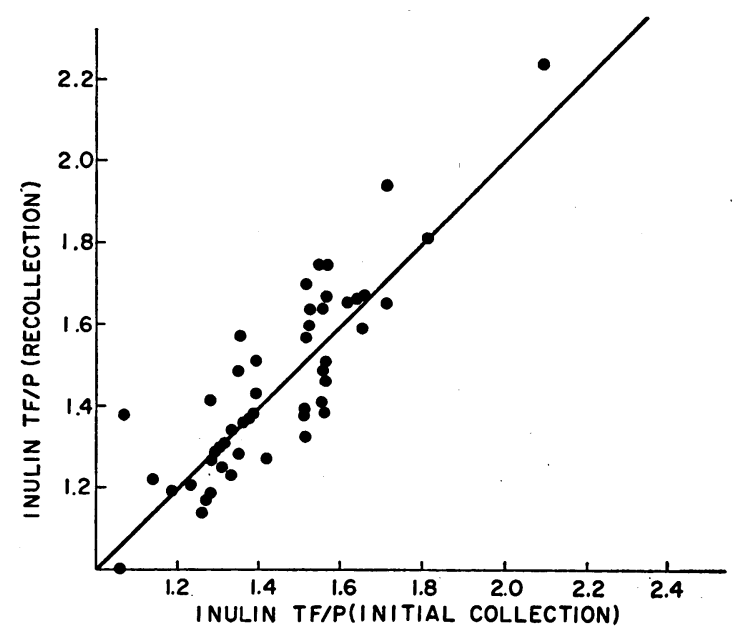

Fig. 1. EFFect of ReCOLlection on PROXIMAL tUbUle FLUID TO PLASMA (TF/P) INULIN DURING CONTINUED SALINE INFUSION IN SIX DOGS. 
TABLE II

Hydropenia control

\begin{tabular}{ccccc}
\hline \hline $\begin{array}{c}\text { Tubule } \\
\text { TF/P*inulin }\end{array}$ & $\begin{array}{c}\text { Initial } \\
\text { collection } \\
\text { TF }\end{array}$ & $\begin{array}{c}\text { First } \\
\text { recollection } \\
\text { TF/P inulin }\end{array}$ & $\begin{array}{c}\text { Second } \\
\text { recollection } \\
\text { TF/P inulin }\end{array}$ & $\begin{array}{c}\text { Third } \\
\text { recollection } \\
\text { TF/P inulin }\end{array}$ \\
\hline 1 & 1.52 & 1.60 & 1.64 & 1.49 \\
2 & 1.56 & 1.75 & 1.53 & 1.51 \\
3 & 1.51 & 1.70 & 1.39 & 1.33 \\
4 & 1.39 & 1.51 & 1.43 & \\
5 & 1.35 & 1.57 & 1.49 & 1.35 \\
6 & 1.71 & 1.94 & 1.65 & \\
7 & 2.10 & 2.24 & & \\
8 & & 1.51 & 1.57 & \\
\hline
\end{tabular}

* $\mathrm{TF} / \mathrm{P}=$ tubule fluid to plasma ratio.

tubule fluid inulin, and any variation in the physiologic state of the animal between collections.

Hydropenia controls. The effect of recollection during prolonged hydropenia is illustrated by the experiment in Table II. Up to three recollections were made (each related to the initial collection). The results of 63 such paired collections in seven dogs are summarized in Figure 2. Again, deviations from the identity line occur in both directions. Scatter is greater than in the saline control group. The mean change in inulin $\mathrm{TF} / \mathrm{P}$ was $-0.04(\mathrm{SE} \pm 0.021)$. The points from one aberrant experiment are separately identified in Figure 2. All inulin $\mathrm{TF} / \mathrm{P}$ ratios in the recollections in this animal were lower than in the control period. During this experiment, urine flow and sodium excretion increased spontaneously between collections. The reasons for the changes in urine flow and sodium excretion and inulin $\mathrm{TF} / \mathrm{P}$ are unclear. Since this experiment did not differ technically from others in this group, the data are included in the statistical analysis.

Isotonic saline infusion. The change in inulin $\mathrm{TF} / \mathrm{P}$ following isotonic saline infusion is indicated in the typical experiment in Table III. Here, all ratios but one decreased after saline infusion. The detailed protocol of a recollection experiment including the hydropenia, saline infusion, and renal artery clamping phases is recorded in Table IV. Figure 3 shows the inulin $\mathrm{TF} / \mathrm{P}$ ratios for 56 recollections after saline infusion in nine dogs compared with the ratios obtained from corresponding tubule segments in hydropenia. The mean change in inulin $\mathrm{TF} / \mathrm{P}$ $(-0.29 \mathrm{SE} \pm 0.037)$ was significantly greater than that in the hydropenic control experiments $(\mathrm{p}<0.001)$.
Eight ratios did not decrease after saline. These were not uniformly those from the first tubules from which recollections were made after the saline infusion. The ratios from these tubules were subsequently depressed during continued saline infusion despite constriction of the renal artery (see Figure 4). Seventeen ratios are from two dogs that received mineralocorticoids and vasopressin. These $\mathrm{TF} / \mathrm{P}$ inulin ratios also decreased after saline infusion and were not significantly different from ratios obtained in the other dogs.

Left renal artery clamping. The inulin $\mathrm{TF} / \mathrm{P}$ during renal artery clamping in a saline infusion experiment is recorded in Tables III and IV, along with an indication of the extent to which filtration rate decreased. The per cent reduction in filtration rate was calculated from the decrease in filtration rate of the experimental kidney compared to the control kidney, corrected for any difference between control and experimental filtration rates when the initial sample was collected. Figure 5 summarizes 33 collections from six dogs for which filtration rates were available during clamping and saline infusion compared with collections from the same tubules during hydropenia ; the extent of reduction of filtration rate is indicated by the symbols used. All ratios after clamping were less than the corresponding control values during hydropenia; the change in $\mathrm{TF} / \mathrm{P}$ inulin could not be related to the degree of reduction

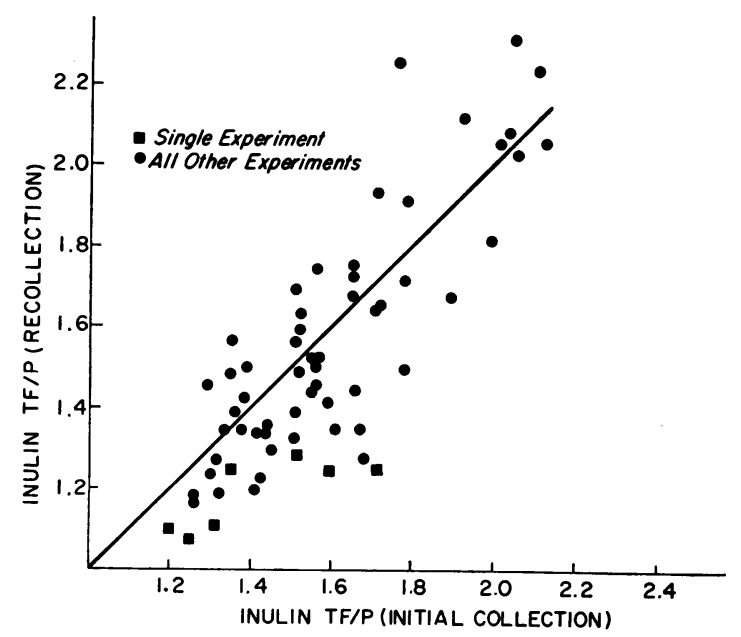

Fig. 2. EFfect of recollection on proximal TF/P INULIN DURING CONTINUED HYDROPENIA IN SEVEN DOGS. Aberrant experiment indicated by $\square$ (see text). 
TABLE III

Isotonic saline infusion

\begin{tabular}{|c|c|c|c|c|}
\hline \multirow[b]{2}{*}{ Tubule } & \multirow{2}{*}{$\begin{array}{l}\text { Hydropenia } \\
\mathrm{TF} / \mathrm{P}^{*} \text { inulin }\end{array}$} & \multirow{2}{*}{$\begin{array}{c}\text { Isotonic } \\
\text { saline } \\
\text { infusion } \\
\text { TF/P inulin }\end{array}$} & \multicolumn{2}{|c|}{$\begin{array}{l}\text { Isotonic saline infusion } \\
\text { with renal artery } \\
\text { clamping }\end{array}$} \\
\hline & & & TF/P inulin & $\% \Delta \mathrm{GFR} \dagger$ \\
\hline 1 & 1.43 & 1.47 & 1.40 & -34 \\
\hline 2 & 1.59 & 1.39 & 1.42 & -56 \\
\hline 3 & 1.45 & 1.36 & & \\
\hline 4 & 1.78 & 1.38 & 1.35 & -57 \\
\hline 5 & 1.63 & 1.41 & 1.28 & -57 \\
\hline 6 & 1.95 & 1.48 & 1.30 & -63 \\
\hline
\end{tabular}

$* \mathrm{TF} / \mathrm{P}=$ tubule fluid to plasma ratio.

$\dagger \% \Delta \mathrm{GFR}=$ corrected change in glomerular filtration rate (see text).

of filtration rate. The inulin $\mathrm{TF} / \mathrm{P}$ in those tubules in which the ratio had not diminished during isotonic saline infusion was uniformly decreased in these later collections. The mean change in inulin $\mathrm{TF} / \mathrm{P}$ for clamping after saline infusion compared to samples from the same tubules in hydropenia was $-0.39(\mathrm{SE} \pm 0.040)$.
This change was not significantly different from that produced by infusion of isotonic saline without clamping. The ratios during clamping are compared with corresponding collections during isotonic saline infusion alone in Figure 4. The five ratios that decreased are from those tubule segments that did not show a decrease during saline infusion alone. The mean change in ratio was -0.07 ( $\mathrm{SE} \pm 0.056)$, a statistically insignificant difference. Individual values were not related to the extent of depression of glomerular filtration rate.

Hypertonic saline infusion. The results of 30 recollections in three dogs given hypertonic saline infusions are compared in Figure 6 with the findings in control collections during hydropenia. In each case fractional sodium and water reabsorption was depressed. The mean decrease in inulin $\mathrm{TF} / \mathrm{P}$ was $-0.42(\mathrm{SE} \pm 0.032)$. The one $\mathrm{dog}$ that received exogenous mineralocorticoids did not differ from the other two.

TABLE IV

Detailed protocol of isotonic saline infusion experiment

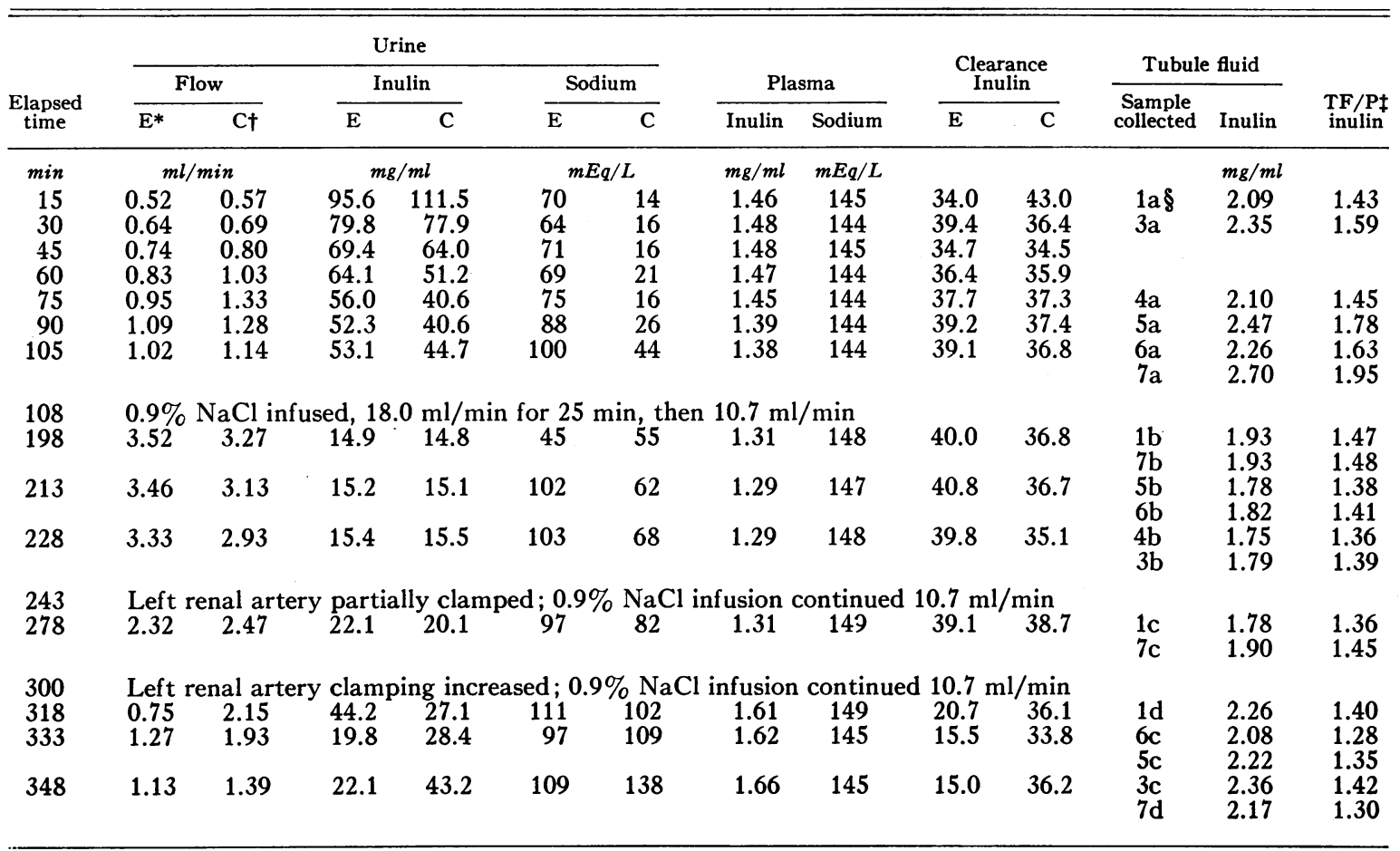

* $\mathrm{E}=$ experimental kidney.

$+\mathrm{C}=$ control kidney.

$\ddagger \mathrm{TF} / \mathrm{P}=$ tubule fluid to plasma ratio.

$\S \mathrm{a}, \mathrm{b}, \mathrm{c}, \mathrm{d}=$ consecutive collections from same tubule segment. 
The mean changes in inulin $\mathrm{TF} / \mathrm{P}$ are summarized in Table $\mathrm{V}$. The mean changes from control in experimental kidney filtration rates of all periods during saline infusion and renal artery clamping are also shown. Isotonic and hy-

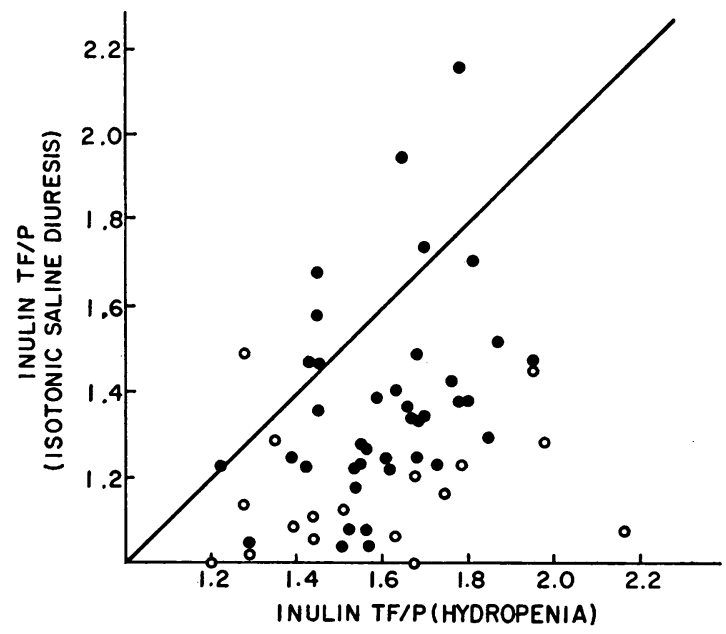

Fig. 3. EFFECT OF ISOTONIC SALINE INFUSION ON PROXIMAL TF/P INULIN IN NINE DOGS. Experiments with exogenous steroids and vasopressin are indicated (O).

pertonic saline infusion raised filtration rate an average of $5.8 \%$ and $2.8 \%$, respectively. The mean decrease after clamping during isotonic saline infusion was $44.7 \%$.

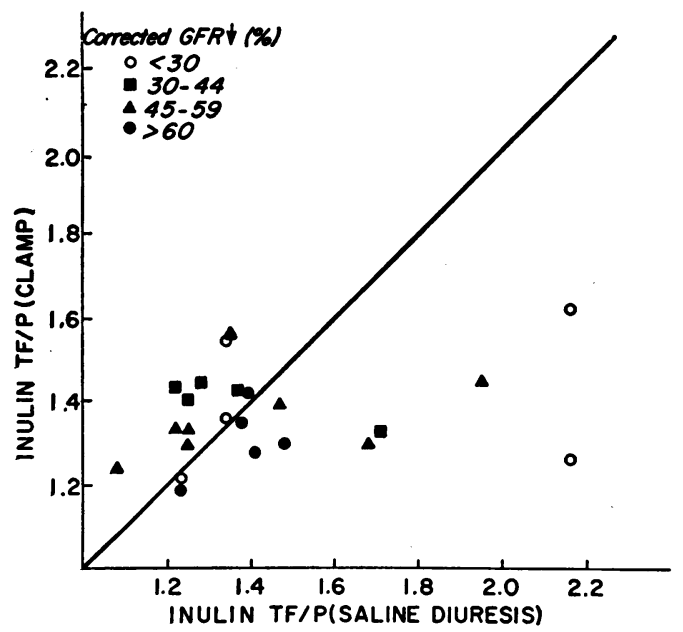

Fig. 4. EFfect of Reduced filtration rate (RENAL ARTERY CLAMPING) DURING SALINE INFUSION ON PROXIMAL TF/P INULIN (COMPARED TO SALINE DIURESIS ALONE) IN FIVE DOGS. Corrected glomerular filtration rate (GFR) decrease explained in text.

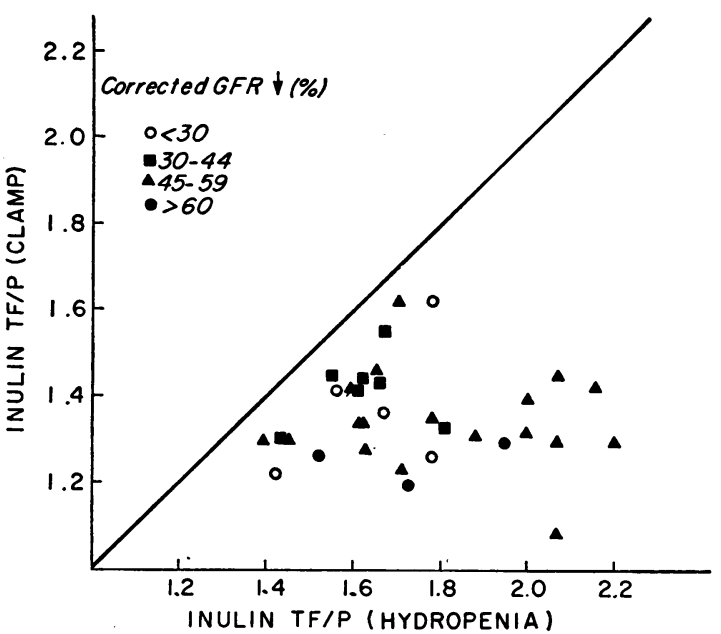

Fig. 5. EFfect of SALINE INFUSion With REDUCED FILTRATION RATE (RENAL ARTERY CLAMPING) ON PROXIMAL TF/P INULIN (COMPARED TO HYDROPENIA) IN SIX DOGS. Corrected GFR decrease explained in text.

The mean per cent changes in fractional reabsorption calculated from the inulin $\mathrm{TF} / \mathrm{P}$ ratios are also recorded in Table $\mathrm{V}$. The change in fractional reabsorption is obtained from the ratio of the per cent change in water reabsorption

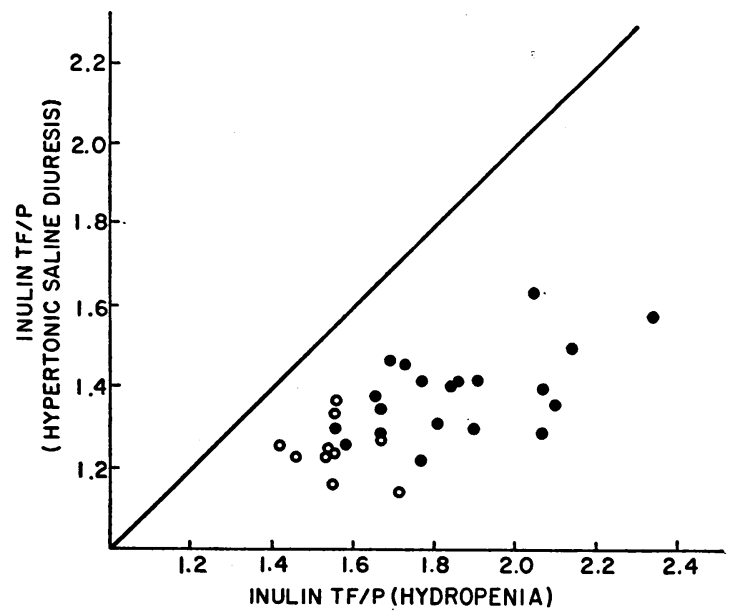

Fig. 6. EFFECT OF HYPERTONIC SALINE INFUSION ON PROXIMAL TF/P INULIN IN THREE DOGS. Experiment with exogenous steroids is indicated $(O)$.

to the initial water reabsorption. Changes of +6.8 and $-8.0 \%$ were obtained in the saline and hydropenia control groups, respectively. Isotonic and hypertonic saline infusion resulted in 31.8 and $41.3 \%$ reductions in fractional reabsorption, respectively. A similar reduction compared 
TABLE V

Summary of inulin data

\begin{tabular}{|c|c|c|c|c|c|}
\hline Experiment & Dogs & $\mathbf{N}$ & $\begin{array}{c}\text { Mean change } \\
\text { inulin } \\
T F / P^{*} \pm S E\end{array}$ & $\begin{array}{l}\text { Mean change } \\
\text { in fractional } \\
\text { reabsorption } \dagger\end{array}$ & $\begin{array}{l}\text { Mean change } \\
\text { in GFR }\end{array}$ \\
\hline & & & & $\%$ & $\%$ \\
\hline Saline control & 6 & 49 & $+0.01 \pm 0.016$ & +6.8 & $+4.7 \ddagger$ \\
\hline Hydropenia control & 7 & 63 & $-0.04 \pm 0.021$ & -8.0 & $+0.7 t$ \\
\hline Isotonic saline vs. hydropenia & 9 & 56 & $-0.29 \pm 0.037$ & -31.8 & $+5.8 t$ \\
\hline Hypertonic saline vs. hydropenia & 3 & 30 & $-0.42 \pm 0.032$ & -41.3 & $+2.8 t$ \\
\hline Clamp after saline vs. saline alone & 5 & 25 & $-0.07 \pm 0.056$ & -8.4 & $-42.3 \S \|$ \\
\hline Clamp after saline vs. hydropenia & 6 & 39 & $-0.39 \pm 0.040$ & -34.2 & $-44.78 \pi$ \\
\hline
\end{tabular}

* $\mathrm{TF} / \mathrm{P}=$ tubule fluid to plasma ratio.

$\dagger$ Calculated from $100 \times \frac{\left(1-\frac{1}{\text { final TF/P inulin }}\right)-\left(1-\frac{1}{\text { initial TF/P inulin }}\right)}{\left(1-\frac{1}{\text { initial TF/P inulin }}\right)}$.

$\ddagger$ Per cent increase in experimental kidney inulin clearance during recollection periods.

$\S$ Per cent decrease in experimental kidney inulin clearance compared to control kidney and corrected for any difference between experimental and control kidneys during control periods.

$\| \mathrm{N}=23$.

I $\mathrm{N}=33$.

with hydropenia $(-34.2 \%)$ persisted after renal artery clamping during saline infusion, whereas changes during saline infusion with renal artery clamping compared with saline infusion alone were not different from the hydropenia control group.

The percentage of filtered sodium excreted is shown in Table VI for all types of experiments from both control and experimental kidneys during initial and recollection phases along with the mean plasma sodium concentration. An average of $6 \%$ (range, 3 to $12 \%$ ) and $3.7 \%$ (range, 3 to $6 \%$ ) of the filtered sodium was excreted during infusion of isotonic and hypertonic saline, respectively. There were no changes in plasma sodium concentration except after infusion of hypertonic saline when the concentration increased from 144 to $160 \mathrm{mEq}$ per $\mathrm{L}$.

\section{Discussion}

These experiments clearly demonstrate that the intravenous infusion of isotonic or hypertonic saline leads to a reduction in the fractional water reabsorption within the proximal tubule of the dog. Since proximal tubule fluid has been shown to be isosmotic to plasma through a full range of osmotic situations in the rat (15) and in the dog (11) and since the reabsorption of water in the proximal tubule has been shown to be dependent upon primary transport of sodium (16-19), it seems justified to interpret the changes in fractional volume reabsorption in the present studies as reflecting changes in fractional sodium reabsorption.

It has been the usual practice in free flow micropuncture experiments to plot tubule fluid to plasma concentration ratios as a function of distance along the tubule. The scatter of points represented by such a plot often makes it difficult to detect changes due to new experimental conditions, particularly since different animals are used for control and experimental situations. In this study, each animal was exposed to both control and experimental conditions. Initial and repeat collections during these periods were made from the same proximal tubule segments. Thus, for a particular recollection pair, the length of tubule involved in reabsorption remained constant and any change in $\mathrm{TF} / \mathrm{P}$ inulin could be interpreted as a change in fractional reabsorption by that tubule. It was shown that simply recollecting from a tubule segment during continued hydropenia or continued saline diuresis did not of itself significantly alter tubule function. This remained true for at least four recollections. The net mean change in $\mathrm{TF} / \mathrm{P}$ inulin in prolonged hydropenia was -0.04 ( $-8 \%$ change in reabsorption), and +0.01 in continued saline diuresis $(+6.8 \%$ change in reabsorption). The validity of the 
TABLE VI

Summary of sodium data

\begin{tabular}{|c|c|c|c|c|}
\hline & \multirow[b]{2}{*}{ Collection } & \multicolumn{2}{|c|}{ Mean $U_{N_{a} V} * / F_{N a} \dagger \times 100$} & \multirow[b]{2}{*}{ Mean P Nat } \\
\hline & & Experimental & Control & \\
\hline Hydropenia control & $\begin{array}{l}\text { Initial } \\
\text { Recollection }\end{array}$ & $\begin{array}{l}0.34 \\
0.49\end{array}$ & $\begin{array}{l}0.57 \\
0.87\end{array}$ & $\begin{array}{l}143.4 \\
143.1\end{array}$ \\
\hline Isotonic saline infusion & $\begin{array}{l}\text { Initial } \\
\text { Saline infusion } \\
\text { Saline +clamp }\end{array}$ & $\begin{array}{l}0.85 \\
6.1 \\
6.7\end{array}$ & $\begin{array}{l}0.83 \\
6.7 \\
9.2\end{array}$ & $\begin{array}{l}143.5 \\
144.3 \\
144.1\end{array}$ \\
\hline Hypertonic saline infusion & $\begin{array}{l}\text { Initial } \\
\text { Saline infusion }\end{array}$ & $\begin{array}{l}0.29 \\
3.2\end{array}$ & $\begin{array}{l}0.43 \\
3.4\end{array}$ & $\begin{array}{l}144.3 \\
159.9\end{array}$ \\
\hline
\end{tabular}

* $\mathrm{U}_{\mathrm{Na}} \mathrm{V}=$ excreted $\mathrm{Na}$ (milliequivalents per minute).

$\dagger \mathrm{F}_{\mathrm{Na}}=$ filtered $\mathrm{Na}$ (milliequivalents per minute).

$\ddagger \mathrm{P}_{\mathrm{Na}}=$ plasma $\mathrm{Na}$ (milliequivalents per liter).

recollection technique as a means of studying changes in proximal salt and water reabsorption appears, thus, to be established.

Isotonic saline infusions in preliminary experiments yielded a lower mean $\mathrm{TF} / \mathrm{P}$ inulin than occurred in hydropenic animals. This depression of $\mathrm{TF} / \mathrm{P}$ inulin could be due to a depression in reabsorption by the tubule or due to an increased filtration rate. Therefore, in most of the recollection experiments reported, collections were obtained from the same tubule segments in hydropenia, isotonic saline infusion, and in isotonic saline infusion with left renal artery clamping. After isotonic saline infusion the mean $\mathrm{TF} / \mathrm{P}$ inulin decreased significantly from hydropenia $(-0.29)$, corresponding to an average depression in sodium reabsorption of $32 \%$. Mean filtration rate increased only $5.8 \%$. The decrease in $\mathrm{TF} / \mathrm{P}$ inulin after saline infusion did not differ significantly in animals treated with exogenous mineralocorticoids and vasopressin from untreated animals.

Left renal artery clamping resulted in a marked reduction in glomerular filtration rate, the decrease being between 30 and $70 \%$ in most instances. After clamping, the kidney became smaller and softer. The tubules were often observed to be narrowed and pale, and the capillary circulation was less rapid. Oil injected into the tubule flowed away less rapidly. It therefore seems certain that the reduced filtration evidenced by the total renal inulin clearance also affected the surface tubules punctured. After saline administration, samples entered the pipette much more rapidly than during hydropenia. After clamping, the samples were collected almost as rapidly as in the diuretic phase without clamping, the fluid entering the pipette, as before, under its own pressure. The mean $\mathrm{TF} / \mathrm{P}$ inulin during isotonic saline infusion with reduced filtration rate did not differ significantly from the depressed $\mathrm{TF} / \mathrm{P}$ inulin of saline infusion. Tubule flow rate would appear to play no important role in determining fractional proximal sodium reabsorption in saline diuresis. The depression of sodium reabsorption within the proximal tubule after isotonic saline administration must then be due to a change in the sodium reabsorbing activity of the tubules.

Although the fraction of the filtered sodium reabsorbed in the proximal tubule appears to remain constant as filtration rate is varied, it is not to be inferred that the fraction of the filtered sodium excreted remains similarly constant. In the data of this study as in many previously reported observations, the fraction of the filtered sodium excreted falls when, other factors remaining constant, glomerular filtration is reduced. The decrease in the fraction excreted is, however, smaller when control excretion is high than when it is low.

Hypertonic saline infusion resulted in an even more reproducible depression of proximal sodium reabsorption. The mean decrease in $T F / P$ inulin was -0.42 , corresponding to a mean decrease in sodium reabsorption of $42 \%$. The mean increase in filtration rate was $2.8 \%$. No clamping experiments were carried out in hypertonic saline infusion, but changes in filtration rate alone were 
again not sufficient to account for the depression in sodium reabsorption by the tubule. However, the filtered load of sodium was increased during hypertonic saline infusion. Since the depression in proximal tubule reabsorption was similar to that found during isotonic saline infusion, it does not appear necessary to distinguish the proximal tubule effects of isotonic and hypertonic saline infusions.

The effect of isotonic and hypertonic saline on the rat proximal tubule as revealed by conventional free flow micropuncture techniques has recently been reported. Lassiter, Mylle, and Gottschalk (9) compared proximal tubule $\mathrm{TF} / \mathrm{P}$ inulin ratios in control rats with those of rats infused with hypertonic saline and could not distinguish between them. Giebisch, Klose, and Windhager (10) obtained similar results in rats infused with hypertonic saline except when sodium excretion exceeded $12 \%$ of the filtered load. In the latter instance, $\mathrm{TF} / \mathrm{P}$ inulin was depressed. These results were considered in harmony with the concept that fractional reabsorption of sodium and water is constant at any point in the proximal convoluted tubule even though the absolute amount of sodium reabsorbed after hypertonic saline infusion was increased. Cortney, Mylle, and Gottschalk (20) reported a decreased mean $\mathrm{TF} / \mathrm{P}$ inulin in the middle third of the proximal tubule of rats infused with isotonic saline. They concluded that absolute sodium reabsorption remained the same after isotonic saline infusion even though fractional reabsorption was depressed. The results of the present study, demonstrating reduction in fractional sodium reabsorption after both isotonic and hypertonic saline administration and after reduction of glomerular filtration rate, indicate that fractional reabsorption is altered considerably in the dog and that the change is not due to changes in the filtered load. The difference between the hypertonic saline infusion experiments in rat and dog is not entirely apparent. Although the recollection technique employed in the dog experiments is probably a more sensitive one, differences as large as those observed in the dog experiments would probably have been detected in the more conventional studies in the rat. The species difference in the handling of salt loads may explain the difference between rat and dog micropuncture studies. Giebisch has suggested that the rat possesses an unusually powerful mechanism for sodium retention (4). Therefore, a similar effect of hypertonic saline in the rat may lead to a smaller depression of proximal sodium transport that might have a later onset. Micropuncture studies of proximal sodium reabsorption in the rat after saline infusion with reduced filtration rate have not been reported.

The effect of saline infusion in this study is consonant with the sodium diuresis studies of DeWardener and co-workers $(1,2)$, Levinsky and Lalone (3), and Blythe and Welt (21) in which an increase in sodium excretion not accounted for by changes in filtration rate was found. Sodium diuresis occurred despite the presence of large doses of mineralocorticoids and vasopressin $(1,3)$. In the experiments reported here, the same decrease in proximal TF/P inulin after isotonic and hypertonic saline was observed in the presence of mineralocorticoids and vasopressin. Therefore, the proximal tubule effect observed is not due to a decrease in the endogenous plasma levels of aldosterone and vasopressin, in agreement with the clearance experiments cited above. It would appear that the proximal tubule effect can also be elicited with smaller salt loads than used in gross kidney experiments by most observers.

The factor responsible for saline diuresis remains unknown. DeWardener and associates showed that the same effect occurred in the denervated kidney. Saline diuresis has now been shown to be unrelated to a long list of maneuvers. It is unrelated to changes in renal plasma flow, in plasma sodium concentration, or in hematocrit and plasma proteins. Adrenalectomy and angiotensin infusion do not prevent saline diuresis (3). Vagotomy, carotid denervation, and upper thoracic sympathectomy did not alter saline diuresis (2). DeWardener and co-workers suggested that an unknown humoral agent was responsible for the effect, but could obtain no clear-cut evidence for a diuretic factor by cross perfusion between a dog undergoing saline diuresis and a normal dog.

Davis has drawn attention to the "escape" phenomenon from mineralocorticoids as possibly being due to this unknown factor (22). The "steroid escape" is not blocked by adrenalectomy and hypophysectomy. Therefore, if this analogy is correct, one would not expect the unknown hormone to originate from the adrenals or the 
pituitary. One need not necessarily postulate a salt-losing hormone in saline diuresis. The data available are also consistent with the existence of a hormone that promotes salt retention and the secretion of which is normally inhibited in some way by administration of saline.

It is clear that the nature and origin of the factor involved in saline diuresis are quite obscure. Similarly, the train of events from the saline administration to depression of sodium reabsorption in the proximal tubule is unknown. In this study as in others no significant change in plasma sodium occurred after isotonic saline infusion. Presumably, the expansion of volume in some body space rather than an alteration in sodium concentration is critical. However, DeWardener and co-workers could not correlate the magnitude of sodium excretion with the expansion of plasma or extracellular fluid volume (2).

This study localizes the inhibition of sodium transport at least to the proximal tubule. Several observers have favored a distal site for such an effect. Stein, Bercovitch, and Levitt (5) and Earley and Friedler (6) favored an inhibition at the distal tubule. Rector and co-workers (7), in studies involving massive infusion of hypotonic saline under conditions of fixed lowered filtration rate and maximal suppression of antidiuretic hormone, found an increase in urine flow, excretion of sodium and potassium, and free water clearance. They concluded that the effect must be on a more proximal portion of the nephron, possibly the proximal tubule. The present study unequivocally places the dominant site of inhibition in the proximal tubule. In fact, the magnitude of depression of proximal tubule reabsorption compared with the ultimate sodium diuresis that occurs suggests that distal reabsorption of sodium is enhanced during saline administration in accord with the inference of Rector and associates (7). Regulation of sodium reabsorption in the proximal convoluted tubule, therefore, must play a major role in the regulation of volume and sodium within the body.

\section{Summary}

1) The effect of infusion of isotonic and hypertonic saline on fluid reabsorption in the dog proximal tubule was investigated by a micropuncture technique involving collection from the same tubule segments during hydropenia and after saline infusion.

2) Controls were 63 paired collections in continued hydropenia and 49 in continued saline diuresis with mean inulin tubule fluid to plasma $(\mathrm{TF} / \mathrm{P})$ changes of -0.04 and +0.01 , respectively.

3) $\mathrm{TF} / \mathrm{P}$ inulin decreased significantly in 56 recollections after isotonic saline infusion $(\Delta=$ $-0.29)$ and in 30 recollections after hypertonic saline infusion $(\Delta=-0.42)$. Sodium reabsorption was depressed 32 and $42 \%$, respectively. Exogenous steroids or vasopressin did not affect the results. Mean fractional sodium excretion increased to $6.4 \%$ in the isotonic saline group and $3.3 \%$ in the hypertonic group.

4) Glomerular filtration rate was decreased by a mean of $45 \%$ by partial renal artery clamping during isotonic saline diuresis. However, mean inulin $\mathrm{TF} / \mathrm{P}$ for 25 recollections was not significantly altered $(\Delta=-0.07)$ when compared to saline diuresis before clamping.

5) These studies indicate that acute isotonic or hypertonic saline infusion results in depression of fractional salt and water reabsorption in the proximal tubule and that the effect is independent of changes in filtration rate.

\section{References}

1. De Wardener, H. E., I. H. Mills, W. F. Clapham, and C. J. Hayter. Studies on the efferent mechanism of the sodium diuresis which follows the administration of intravenous saline in the dog. Clin. Sci. 1961, 21, 249.

2. Mills, I. H., H. E. De Wardener, C. J. Hayter, and W. F. Clapham. Studies on the afferent mechanism of the sodium chloride diuresis which follows intravenous saline in the dog. Clin. Sci. 1961, 21, 259.

3. Levinsky, N. G., and R. C. Lalone. The mechanism of sodium diuresis after saline infusion in the $\mathrm{dog}$. J. clin. Invest. 1963, 42, 1261.

4. Giebisch, G., and E. E. Windhager. Renal tubular transfer of sodium, chloride and potassium. Amer. J. Med. 1964, 36, 643.

5. Stein, R. M., D. D. Bercovitch, and M. F. Levitt. Dual effects of saline loading on renal tubular sodium reabsorption in the dog. Amer. J. Physiol. 1964, 207, 826.

6. Earley, L. E., and R. M. Friedler. Observations on the mechanism of decreased tubular reabsorption 
of sodium and water during saline loading. J. clin. Invest. 1964, 43, 1928.

7. Rector, F. C., Jr., G. Van Giesen, F. Kiil, and D. W. Seldin. Influence of expansion of extracellular volume on tubular reabsorption of sodium independent of changes in glomerular filtration rate and aldosterone activity. J. clin. Invest. 1964, $43,341$.

8. Smith, H. The Physiology of the Kidney. New York, Oxford Press, 1937.

9. Lassiter, W. E., M. Mylle, and C. W. Gottschalk. Net transtubular movement of water and urea in saline diuresis. Amer. J. Physiol. 1964, 206, 669.

10. Giebisch, G., R. M. Klose, and E. E. Windhager. Micropuncture study of hypertonic sodium chloride loading in the rat. Amer. J. Physiol. 1964, 206, 687.

11. Clapp, J. R., J. F. Watson, and R. W. Berliner. Osmolality, bicarbonate concentration, and water reabsorption in proximal tubule of the dog nephron. Amer. J. Physiol. 1963, 205, 273.

12. Führ, J., J. Kaczmarczyk, and C. D. Krüttgen. Eine einfache colorimetrische Methode zur Inulin Bestimmung für Nieren-clearance untersuchungen bei Stoffwechselgesunden und Diabetikern. Klin. Wschr. 1955, 33, 729.

13. Hilger, H. H., J. D. Klümper, and K. J. Ullrich. Wasserrückresorption und Ionentransport durch die Sammelrohrzellen der Säugetierniere. Pflügers Arch. ges. Physiol. 1958, 267, 218.

14. Davidson, W. D., and M. A. Sackner. Simplification of the anthrone method for the determination of inulin in clearance studies. J. Lab. clin. Med. 1963, 62, 351.

15. Gottschalk, C. W. Micropuncture studies of tubular function in the mammalian kidney. Physiologist 1961, 4, 35.

16. Ullrich, K. J., B. Schmidt-Nielsen, R. O'Dell, G. Pehling, C. W. Gottschalk, W. E. Lassiter, and M. Mylle. Micropuncture study of composition of proximal and distal tubular fluid in rat kidney. Amer. J. Physiol. 1963, 204, 527.

17. Windhager, E. E., and G. Giebisch. Micropuncture study of renal tubular transfer of sodium chloride in the rat. Amer. J. Physiol. 1961, 200, 581.

18. Kashgarian, M., H. Stöckle, C. W. Gottschalk, and K. J. Ullrich. Transtubular electrochemical potentials of sodium and chloride in proximal and distal renal tubules of rats during antidiuresis and water diuresis (diabetes insipidus). Pflügers Arch. ges. Physiol. 1963, 277, 89.

19. Giebisch, G., R. M. Klose, G. Malnic, W. J. Sullivan, and E. E. Windhager. Sodium movement across single perfused proximal tubules of rat kidneys. J. gen. Physiol. 1964, 47, 1175.

20. Cortney, M. A., M. Mylle, and C. W. Gottschalk. Renal water and solute reabsorption in isotonic saline loaded rat (abstract). Physiologist 1964, $7,108$.

21. Blythe, W. B., and L. G. Welt. Dissociation between filtered load of sodium and its rate of excretion in the urine. J. clin. Invest. 1963, 42, 1491.

22. Davis, J. O. Two important frontiers in renal physiology. Circulation 1964, 30, 1. 